\title{
Article \\ Hybrid Self-Reacting Friction Stir Welding of AA 6061-T6 Aluminium Alloy with Cooling Assisted Approach
}

\author{
Kishan Fuse *(D) and Vishvesh Badheka \\ School of Technology, Pandit Deendayal Petroleum University, Gandhinagar 382007, India; \\ Vishvesh.Badheka@spt.pdpu.ac.in \\ * Correspondence: kishan.fuse@sot.pdpu.ac.in
}

check for

updates

Citation: Fuse, K.; Badheka, V. Hybrid Self-Reacting Friction Stir Welding of AA 6061-T6 Aluminium Alloy with Cooling Assisted Approach. Metals 2021, 11, 16. https://dx.doi.org/ 10.3390/met11010016

Received: 7 December 2020

Accepted: 21 December 2020

Published: 24 December 2020

Publisher's Note: MDPI stays neutral with regard to jurisdictional claims in published maps and institutional affiliations.

Copyright: () 2020 by the authors. Licensee MDPI, Basel, Switzerland. This article is an open access article distributed under the terms and conditions of the Creative Commons Attribution (CC BY) license (https: / / creativecommons.org/ licenses/by/4.0/).

\begin{abstract}
In the present work, self-reacting friction stir welding of $6 \mathrm{~mm}$ thick $\mathrm{Al}$ 6061-T6 was processed considering two novel approaches as different temperatures of the water $\left(1{ }^{\circ} \mathrm{C}\right.$ and $30^{\circ} \mathrm{C}$ ), and methods of use (spraying and enveloping top surface) using water as cooling media. The four experiments as natural air cooling (NAC), spraying with room temperature water mist (S-RM), spraying with ice water mist (S-IM), and cooling with room temperature water jet (C-RJ) were performed. The thermal profile, microstructure, microhardness, and tensile properties were investigated for all the joints. The lowest hardness location was heat affected zone in NAC and it was the boundary of the thermo-mechanically affected zone and weld nugget zone in all cooling assisted joints. The C-RJ cooling assisted joint resulted in the highest tensile strength of $189.16 \mathrm{MPa}$ which is $8.17 \%$ higher than the conventional self-reacting friction stir welded joint.
\end{abstract}

Keywords: self-reacting; cooling; friction; welding; microhardness; microstructure; underwater

\section{Introduction}

In recent years, the demand for lightweight alloys such as aluminium (Al) alloys is increasing rapidly. However, joining of these alloys presents great challenges. The use of conventional fusion welding techniques for joining such alloys is susceptible to generate defects such as oxidation, distortion, porosity, and solidification cracks in joints as the materials are joined by melting and solidification in fusion welding techniques [1,2]. The solidstate joining techniques are a better solution for joining these alloys. The researchers at The Welding Institute (London, UK) invented a solid-state joining technique known as friction stir welding (FSW) in 1991 for joining aluminium alloys [3-5]. In the friction stir welding technique, the material coalescences occur at temperature $0.5-0.7$ times the melting temperature of the parent material i.e., below the melting point of the material [6,7]. Thus, avoiding defects associated with joining with conventional fusion welding techniques.

In conventional FSW, the tool consists of an upper shoulder and pin. The pin length is always $0.8-0.9$ times the thickness of the workpiece. The excess plunge of the pin may create a groove on the backing plate. It also causes trapping of backing plate material in the joint. The backing plate also acts as a cooling media and dissipates heat rapidly by convection heat transfer leading to weld cracking in the joint [8]. Moreover, the use of conventional FSW in the joining of curved profiles and hollow extrusions is highly challenging due to the presence of a backing plate [3]. This necessitates certain modifications in conventional FSW.

The self-reacting friction stir welding (SRFSW) also known as Bobbin tool friction stir welding (BTFSW) is one of the variants of conventional FSW. The SRFSW tool consists of an additional shoulder known as the lower shoulder. The lower shoulder supports the workpiece and thus eliminates the need for a backing plate. The two-shoulder configuration of the SRFSW tool exhibits many advantages such as uniform heat generation on both sides of the workpiece, complete penetration joint, less cross-seam distortion, and less axial force, etc. [9]. The researchers explored conventional FSW through many aspects such as the investigation of the effect of process parameters [10,11], the effect of tool 
profiles [12], numerical modelling of FSW [13], and optimization of FSW [14-16]. Enhancing the mechanical properties of welded joints using different processing conditions of cooling assisted mode has remained a thrust area in conventional FSW. Mehta et al. [17] investigated conventional and water cooling assisted FSW of Al-Mg dissimilar welding and reported more tensile strength with water cooling assisted FSW. Patel et al. [18] performed AlTi dissimilar welding using different processing cooling mediums such as compressed air, $\mathrm{CO}_{2}$, and controlled water flow and found a noticeable effect on tensile properties. Peng et al. [19] performed conventional friction stir welded AA5A06-AA6061 joints using forced air cooling and natural cooling. The various processing media such as water [20-23], $\mathrm{CO}_{2}$ gas [24], liquid $\mathrm{CO}_{2}$ [25], dry ice [26], compressed air [27] were investigated for enhancing mechanical properties of friction stir welded joints.

SRFSW technique has been explored to study the effect of process parameters (rotation speed, welding speed) on mechanical and microstructural properties. Li et al. [3] studied the effect of tool rotation speed on SRFSWed Al 6082-T6 alloy. They found the lowest strength at 600 rotation speed. Zhou et al. [28] investigated the effect of tool rotation on SRFSWed AZ61 magnesium alloy. They found that grain size depends on the rotation speed. Several researchers [1,29] conducted similar studies investigating the effect of rotation speed. Another process parameter i.e., welding speed also affects mechanical properties during SRFSW. Li et al. [30] investigated Mg-6Al-1Zn alloy welded joints using SRFSW at various welding speeds and found pore defects at low welding speed due to inadequate mixing of plastic material. The effect of welding speed has also been investigated by several researchers [31-34].

The literature study revealed that limited research was carried out to enhance the strength of joints formed with SRFSW using different cooling mediums. Sahu et al. [8] attempted the use of inert gas medium during SRFSW of AZ31 Mg alloy for enhancing mechanical properties. The results depicted improved joint properties under inert atmospheric welding. Zhao et al. [35] used water cooling in SRFSW of 6063-T6 alloy and found improved tensile strength compared with conventional SRFSW.

SRFSW works on a similar principle to CFSW. However, it is necessary to understand this novel technique in-depth as it doesn't need a backing plate because the tool enters from the side of the joining workpieces, and hence no axial force present in this technique. Moreover, an additional shoulder (lower shoulder) adds more frictional heat during the process. Frictional heat generated causes high temperature [36] and temperature determines the thermomechanical behaviour of the joint [37]. This can result in a different response in SFRSW compared to CFSW when performed using water cooling media and hence, it is necessary to understand the SRFSW technique with a water cooling assisted approach. Water is having very high specific heat than air. Specific heat is the capacity of the substance to absorb heat. Higher specific heat of the water must provide a higher cooling rate during welding compared to air. Specific heat of a substance depends on temperature difference $(\Delta \mathrm{T})$ between substance and atmosphere. Thus, the temperature of the water plays an important role while considering water as cooling media during welding as it directly affects $\Delta \mathrm{T}$ and a higher value of $\Delta \mathrm{T}$ indicates more heat absorption. Additionally, water-assisted cooling can affect differently with different methods of using it i.e., spraying water at the top surface of the joint [35] or performing underwater welding by the continuous supply of the water on the top surface of the joint. Although the research on SRFSW is widening concerning different aspects of the process, as per the author's knowledge, no research articles are available on water cooling media assisted self-reacting friction stir welding of $\mathrm{Al}$ 6061-T6 considering the different temperature of the water and methods of using it. The current work investigated the effect of the water as cooling media on self-reacting friction stir welded Al 6061-T6 joints considering two novelties: (i) Two different temperatures of the water $\left(1{ }^{\circ} \mathrm{C}\right.$ and $\left.30^{\circ} \mathrm{C}\right)$, (ii) Two method of using water. These different variants are further compared with conventional air-cooled SRFSW samples. 


\section{Materials and Methods}

The $6 \mathrm{~mm}$ thick AA 6061-T6 aluminium alloy of dimension $65 \mathrm{~mm} \times 65 \mathrm{~mm}$ was used as the base material for the study. The joining was performed in a butt configuration using a vertical milling machine. The chemical composition and mechanical properties of base metal (BM) are presented in Table 1. The SRFSW tool was manufactured using the H13 tool steel material. For the tool, the top and bottom shoulder diameter were $24 \mathrm{~mm}$, and four spiral grooves each on the top and bottom shoulder surface were inscribed for the movement of material from outside towards the pin of the tool. A tool with a cylindrical pin of diameter $8 \mathrm{~mm}$ with three flats and a length $6 \mathrm{~mm}$ was used during the experiments as shown in Figure 1. The preliminary trials were conducted with different combinations of rotational speed and welding speed from the available working window of the machine and the joints were observed for visual defects. Based on extensive preliminary trial results, the tool rotation speed and travel speed were fixed at $380 \mathrm{rpm}$ and $31.5 \mathrm{~mm} / \mathrm{min}$ respectively. The plunge depth of $0.05 \mathrm{~mm}$ was set of top and bottom shoulders. The experiments were performed at four different processing conditions as natural air cooling, spraying with room temperature water mist, spraying with ice water mist, and cooling with room temperature water jet and designated as NAC, S-RM, S-IM, and C-RJ respectively. In natural air cooling experiments, the welded samples were cooled in an open environment naturally by air cooling. NAC cooling assisted joints are sometimes referred to as conventional SRFSW joints or as welded joints throughout the paper. In S-RM experiments, the water mist at room temperature of $30^{\circ}$ was used as cooling media, and it was sprayed with a constant flow rate of 0.1 litre per minute on the top surface of the workpiece behind the trailing edge of the top shoulder. The S-IM experiments were performed in the same way as S-RM with only a change in the temperature of the water mist. The ice water at a temperature of $1{ }^{\circ} \mathrm{C}$ was sprayed in S-IM. During S-IM and S-RM, the spraying was carried out along the shoulder region only, and the water spraying source was kept about $25 \mathrm{~mm}$ above the workpiece surface and $25 \mathrm{~mm}$ behind the tool. The spray angle was maintained at $30^{\circ} \mathrm{C}$ with the surface of the workpiece. In C-RJ experiments, top surface of the joining material was kept fully submerged with water throughout the experiment with room temperature water jet. Figure 2 shows schematic of experimental set-up used for performing experiments.

Table 1. The chemical composition and mechanical properties of base metal.

\begin{tabular}{cccccccccccc}
\hline & \multicolumn{4}{c}{ Chemical Composition (wt \%) } & \multicolumn{4}{c}{ Mechanical Properties } \\
\hline Si & Fe & Cu & Mn & Mg & Cr & Zn & Al & $\begin{array}{c}\text { UTS } \\
(\mathbf{M P a})\end{array}$ & $\begin{array}{c}\text { Elongation } \\
(\%)\end{array}$ & $\begin{array}{c}\text { Hardness } \\
(\mathbf{H V})\end{array}$ \\
\hline 0.457 & 0.553 & 0.173 & 0.106 & 0.937 & 0.266 & 0.010 & Bal & 282 & 21 & $80-90$ \\
\hline
\end{tabular}
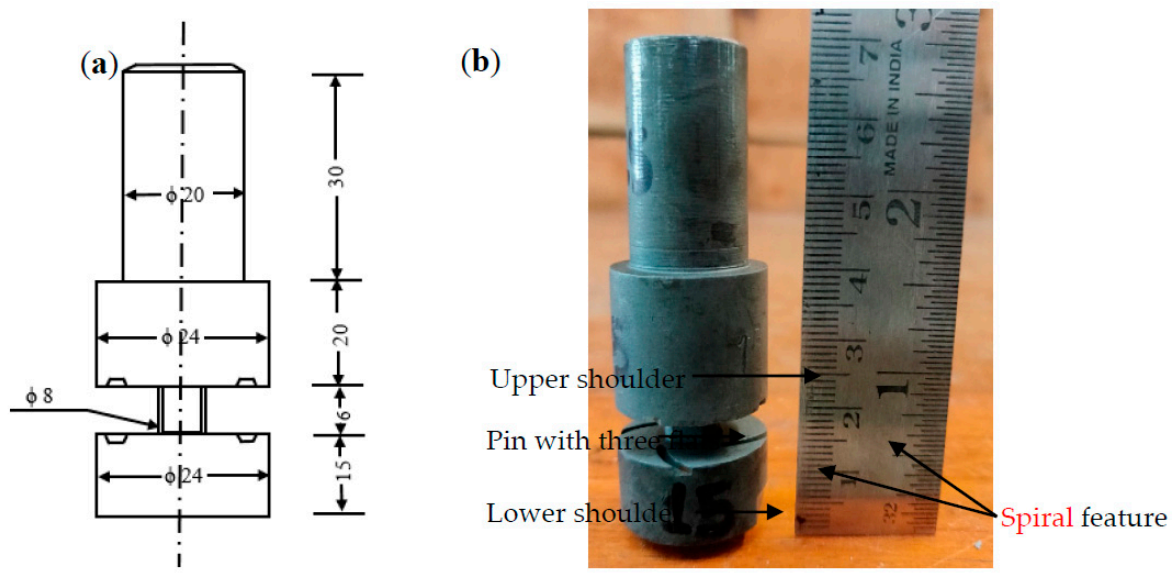

Figure 1. Bobbin tool used during experiments (a) Schematic of tool (b) Manufactured tool. 

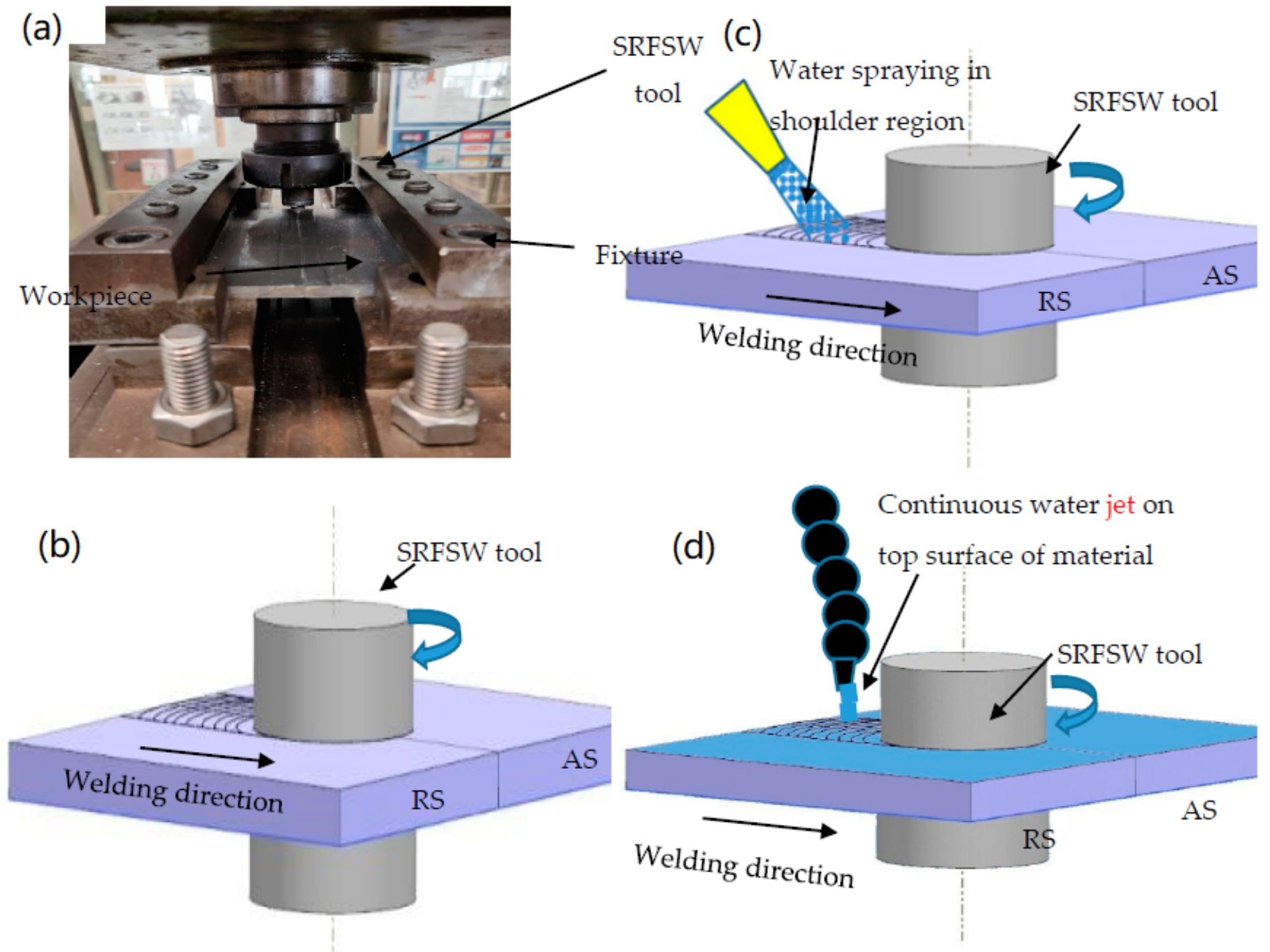

Figure 2. (a) Experimental set-up, (b-d) schematic of NAC, S-RM and S-IM, and C-RJ cooling assisted approach respectively.

After welding, the samples were cut transverse to the welding. The cut samples were prepared for metallographic study by polishing them and further etched using Keller's reagent $\left(\mathrm{HNO}_{3}: \mathrm{HCl}: \mathrm{HF}: \mathrm{H}_{2} \mathrm{O}=2.5: 1.5: 1: 95\right.$ vol.\%). Metallographic examinations were carried out by optical microscopy (Olympus GX51, Tokyo, Japan). The average grain size in different zones of the joints and BM was using Electron Backscatter Diffraction (EBSD) (JEOL, Tokyo, Japan; Model: 6500F). Microhardness measurements were done along the centerline of polished cross-sections using Vickers microhardness indentation machine (Innovatest Europe BV NEXUS 4302, Borgharenweg, The Netherlands) at an interval of $1 \mathrm{~mm}$. The load of $300 \mathrm{~g}$ for $10 \mathrm{~s}$ dwell time was set during measurement. The K-type thermocouple was used for temperature measurement on the advancing side (AS) of each sample. The size of the probe of the thermocouple was $\Phi 2 \mathrm{~mm}$ and it was placed $15 \mathrm{~mm}$ away from the weld centerline. Tensile testing specimens were prepared according to ASTM E8M standards. Tensile properties reported are the average strength of three tensile specimens. The tensile testing was performed by a computer-controlled universal testing machine (FSA FSA/M-100, Maharashtra, India) at crosshead speed $1 \mathrm{~mm} / \mathrm{min}$ at room temperature. Figure 3 shows the flow-chart of the methodology followed during the present study. 


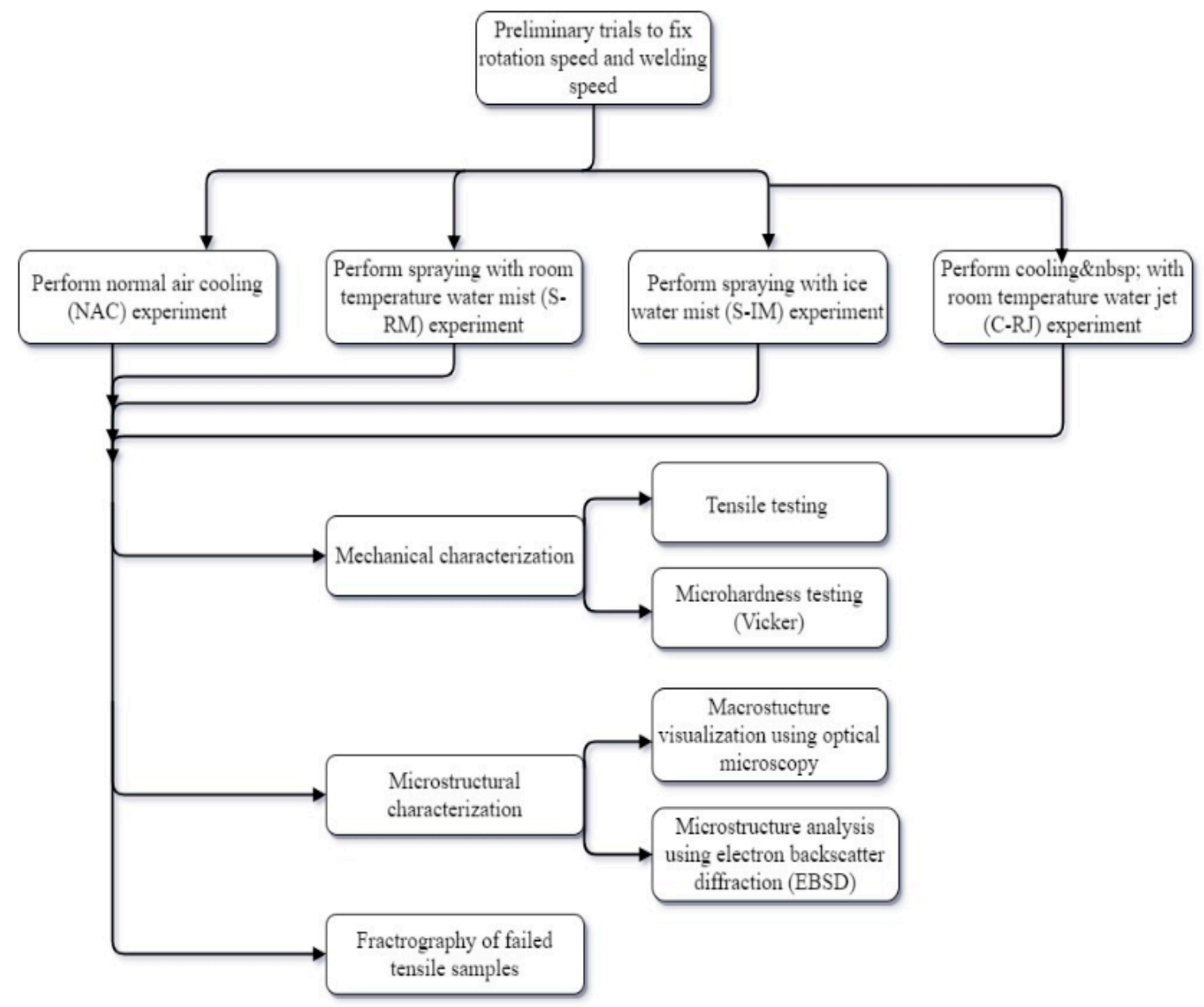

Figure 3. Flow-chart of the adopted methodology.

\section{Results and Discussion}

\subsection{Thermal Cycles}

The thermal cycles experienced by welded regions of the workpiece during and after welding influence microstructure and thus mechanical properties of the joints. Figure 4 shows the welding thermal cycle of different cooling conditions. As shown in the figure, the temperature rises to a peak and further drops in all the conditions except C-RJ. In the $\mathrm{C}-\mathrm{RJ}$ joints, the temperature was stable for a long period. The maximum temperature observed in NAC, S-RM, S-IM, C-RJ was $580 \mathrm{~K}, 514 \mathrm{~K}, 488 \mathrm{~K}$, and $376 \mathrm{~K}$ respectively. The melting point of Al6061-T6 is nearly $923 \mathrm{~K}$. The maximum temperature generated in all the welding experiments was well below melting point of parent material indicating solid state joining of SRFSW. The cooling systems resulted in the reduction of peak temperature by $11.39 \%, 15.71 \%$, and $35.05 \%$ compared to peak temperature during normal air cooling. This reduction in peak temperature of the water cooling assisted joints can be attributed to the exceptionally high value of specific heat of water $(4.187 \mathrm{KJ} / \mathrm{Kg} \mathrm{K})$ and its high latent heat of boiling which carried away a large amount of heat during welding. S-IM showed less peak temperature compared to S-RM. This can be attributed to an improved heat transfer rate at a reduced temperature of the water in S-IM. The artificial aging temperature of the Al6061-T6 alloy is $150{ }^{\circ} \mathrm{C}$. 


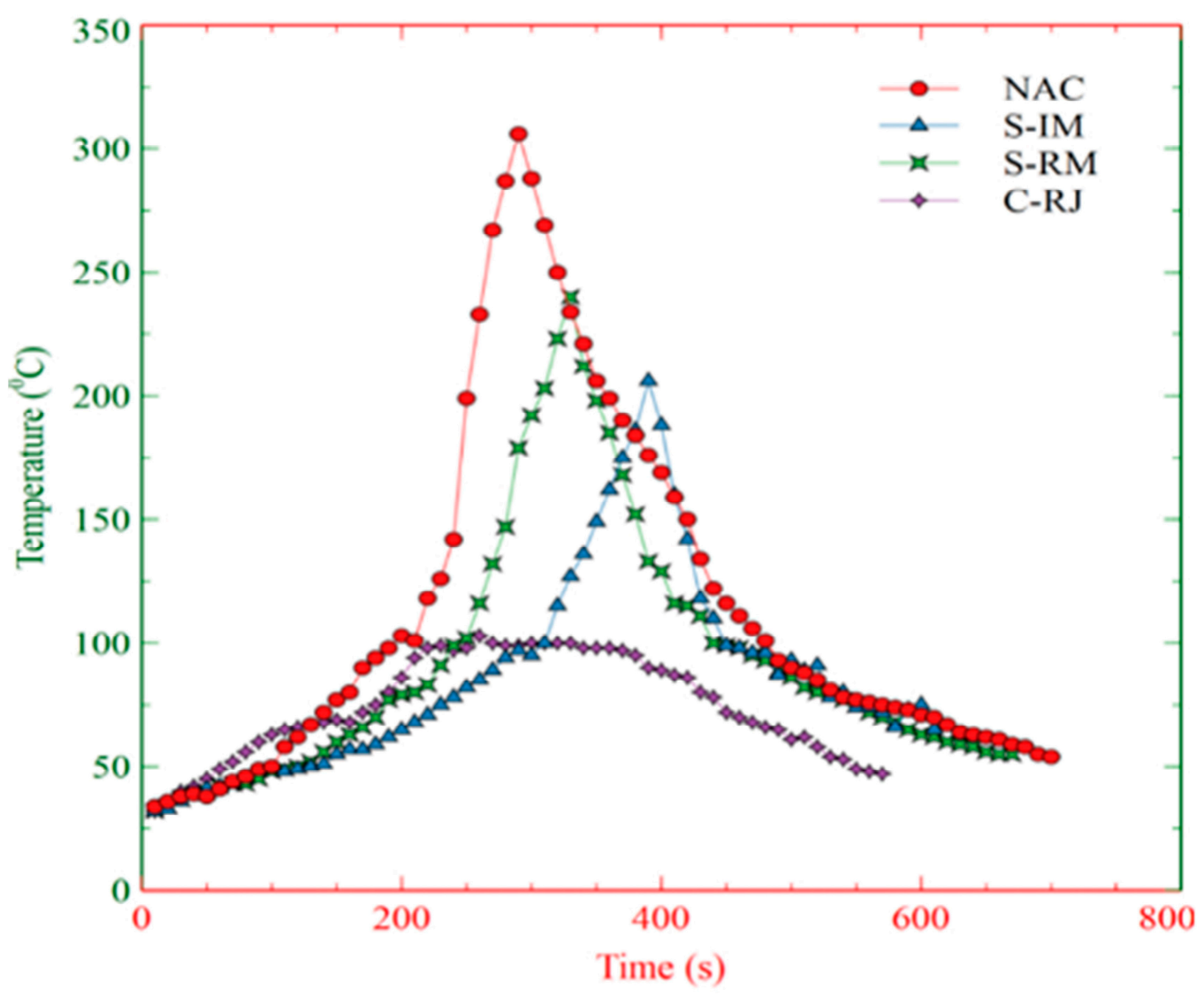

Figure 4. Welding thermal cycle for different cooling conditions.

In the thermal cycles, the intermediate stage of welding between $150{ }^{\circ} \mathrm{C}$ and peak temperature is the temperature rise stage, and the slope of this stage (the average temperature rise) is termed as heating rate. Similarly, the stage of welding between peak temperature and $150{ }^{\circ} \mathrm{C}$ is the temperature falling stage, and the slope of this stage (the average temperature fall) is termed as cooling rate. The heating rate and cooling rate for C-RJ was not calculated because it never crossed $150^{\circ} \mathrm{C}$. The calculated heating rate for NAC, S-RM, and S-IM is $3.28^{\circ} \mathrm{C} / \mathrm{s}, 1.86^{\circ} \mathrm{C} / \mathrm{s}$, and $1.65{ }^{\circ} \mathrm{C} / \mathrm{s}$ respectively. The drop in heating rate in S$\mathrm{RM}$ and S-IM was due to the influence of the water mist. On the other hand, the tcalculated cooling rate was found to be $1.2^{\circ} \mathrm{C} / \mathrm{s}, 1.76^{\circ} \mathrm{C} / \mathrm{s}$, and $2.43^{\circ} \mathrm{C} / \mathrm{s}$ corresponding to NAC, $\mathrm{S}-\mathrm{RM}$, and S-IM. The increase in the cooling rate signifies that water carried away heat more efficiently than air. In cooling by spraying technique, S-IM showed more cooling rate $\left(2.43^{\circ} \mathrm{C} / \mathrm{s}\right)$ compared to S-RM $\left(1.76{ }^{\circ} \mathrm{C} / \mathrm{s}\right)$. The increase in the cooling rate in S-IM to S-RM was due to more heat transfer rate of ice water compared to normal room temperature water. This can be attributed to the temperature difference between plate temperature and temperature of used water because the temperature difference is directly related to the heat transfer rate. The higher the temperature difference, more will be the heat transfer rate.

\subsection{Macrostructure of the Joint}

The surface morphologies of the self-reacting friction stir welded joints under different cooling conditions are shown in Figure $5 \mathrm{a}-\mathrm{d}$. Defect-free joints are observed for all the samples. The top surfaces of normal air cooling welded samples are observed with rough marks of the shoulder, while a smooth surface is obtained in all other samples. This can be attributed to rapid cooling induced by water at the surface of joints restricting the capability of the material to flow around the tool, resulting in a smoother surface [38]. From Figure 5, it can be visually observed that the amount of flash formed is more in case of normal air cooling than remaining conditions. This is because, in NAC, the temperature produced 
was much higher resulting in more material to be plasticized and ejected out of the weld area in the form of flash [23]. Very little to no flash is seen during other joints because of the continuous dissipation of friction heat generated by the shoulder in the water on the top surface of the workpiece. The surface morphology study revealed that the formation of flash is directly correlated with the surface temperature of the workpiece under different cooling conditions.
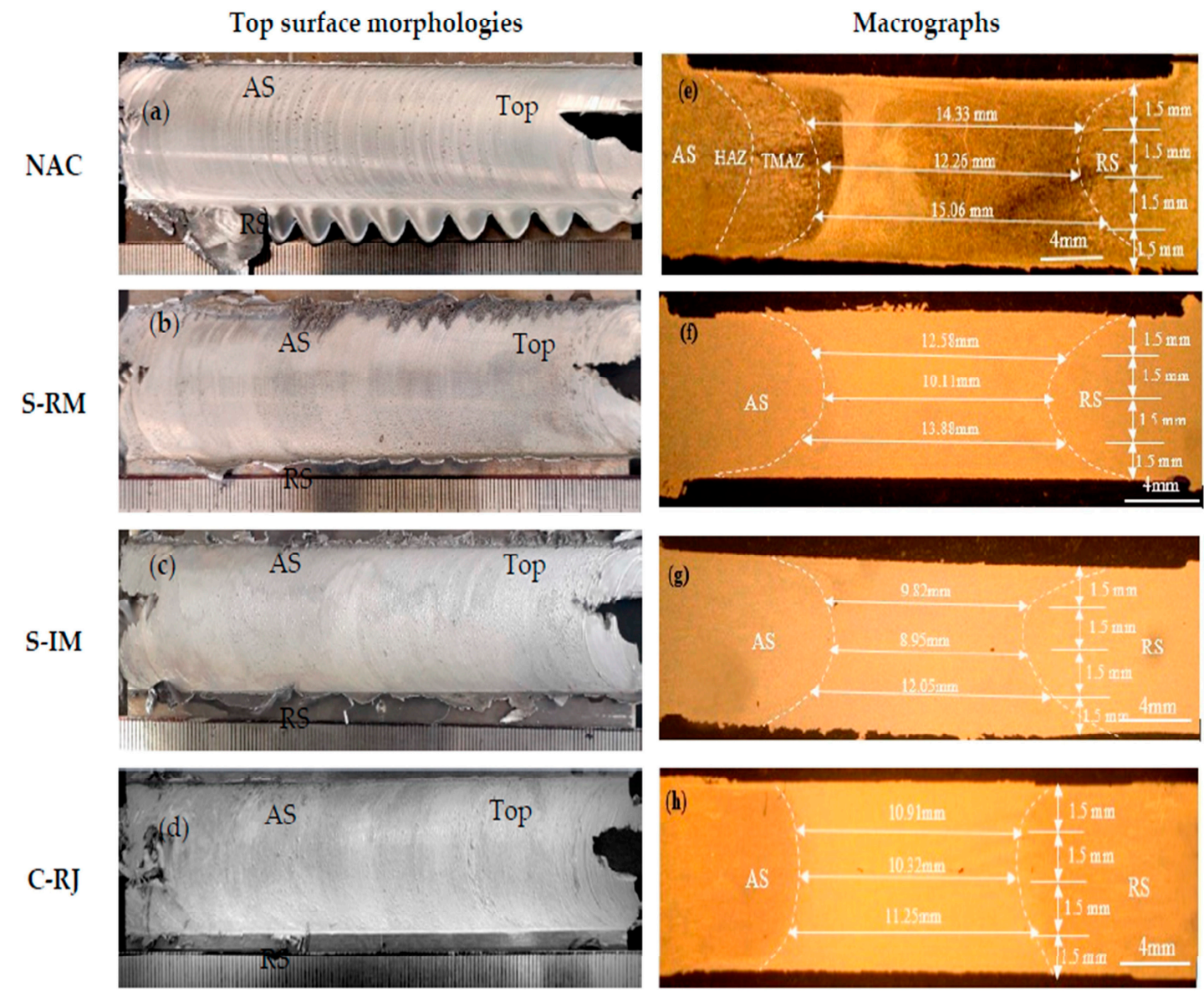

Figure 5. (a-d) Top surface morphologies and (e-h) macrographs of bobbin tool friction stir welded joints for the different cooling conditions.

The macrostructure of self-reacting friction stir welded joints in as-welded (NAC) and different cooling conditions is shown in Figure 5e-h. All the samples create hourglass shape SZ and exhibited defect-free joint with four microstructural zones: weld nugget zone (WNZ), thermo-mechanical affected zone (TMAZ), heat affected zone (HAZ), and BM. The dimensions of width of weld nugget zone at top, middle, and bottom are given in Table 2. It was observed that the width of the top, middle, and bottom parts of WNZ of the NAC joint was higher than all other cooling methods. The maximum reduction in width was found in the case of S-IM followed by S-RM compared to NAC joints. This can be attributed to the fact that superfluous heat on the surface of the workpiece was absorbed by water mist. It can be observed that the width of the bottom part in S-RM, S-IM, and C-RJ is significantly more than that of the width of the top part. This is because external cooling was applied only on the top surface of the samples. Because of this cooling arrangement, the heat was quickly dissipated from the top surface to the cooling medium resulting in a narrowing width of WNZ at the top part. 
Table 2. Dimensions of width of WNZ.

\begin{tabular}{cccc}
\hline Cooling Type & Top $(\mathbf{m m})$ & Middle $(\mathbf{m m})$ & Bottom $(\mathbf{m m})$ \\
\hline NAC & 14.33 & 12.26 & 15.06 \\
\hline S-IM & 12.58 & 10.11 & 13.88 \\
\hline S-RM & 9.82 & 8.95 & 12.05 \\
\hline C-RJ & 10.91 & 10.32 & 11.25 \\
\hline
\end{tabular}

\subsection{Microstructure of the Joint}

Figure 6 shows the typical microstructure in the different zones of the SRFSW joint welded with the C-RJ cooling approach. The base metal has an elongated coarse grain as shown in Figure 6a. The heat-affected zone which undergoes only thermal cycling exhibit uniform grain size distribution compared to BM as shown in Figure $6 \mathrm{~b}$. Figure $6 \mathrm{c}$ indicates an interface of TMAZ and WNZ. Grains in TMAZ region appeared bended and elongated due to mechanical rotation of tool which causes stirring shearing effect. Partial recrystallization in TMAZ results in some fine equiaxed grains. Figure $6 \mathrm{~d}$ shows grain morphology in WNZ which was characterized by uniform distribution of fine equiaxed grains. The pin of the tool produced large plastic deformation in SZ which forms new grain boundaries.
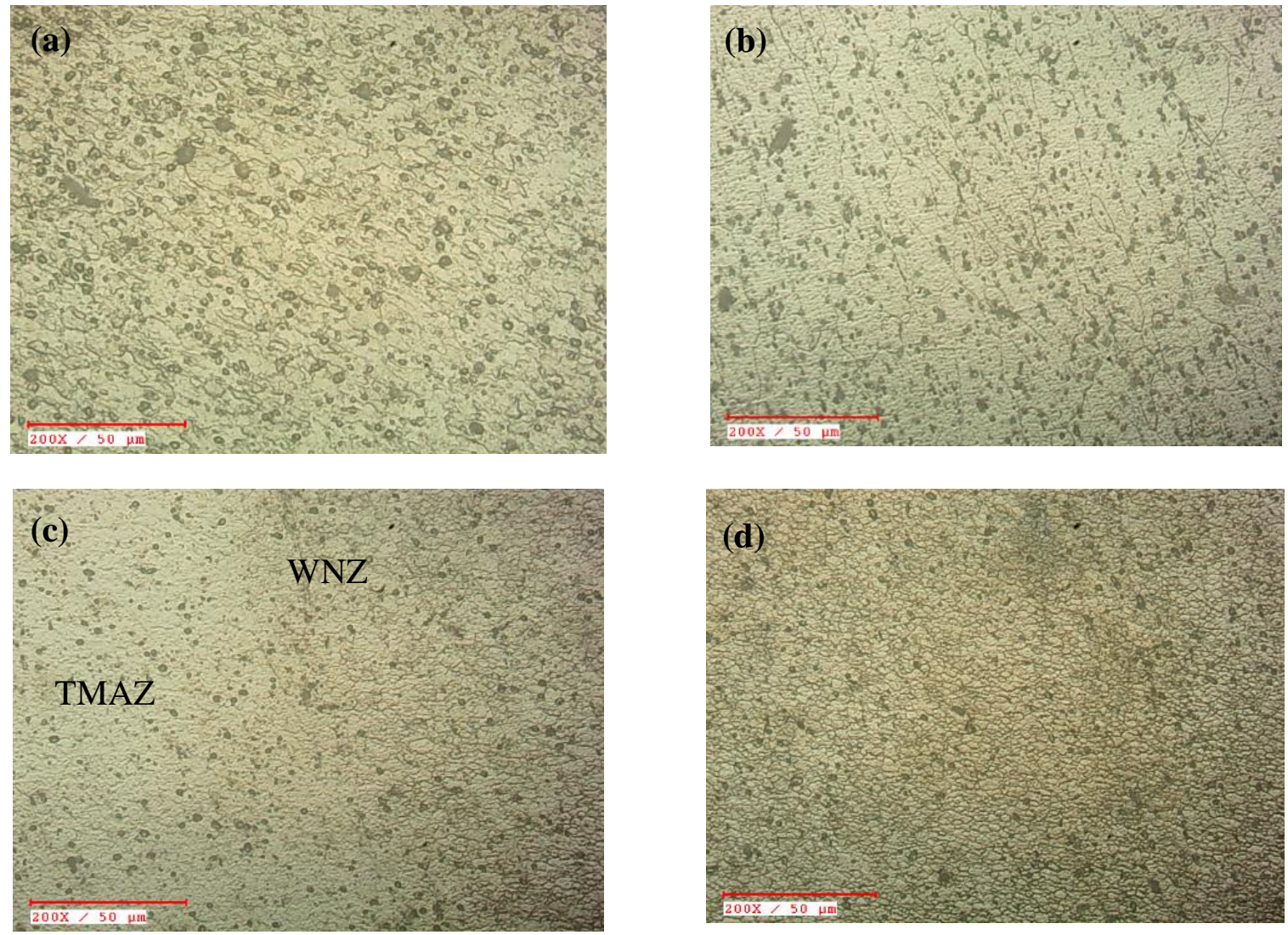

Figure 6. Microstructures observed with an optical microscopy of the typical joint welded with room temperature water jet cooling approach (C-RJ): (a) BM (b) HAZ (c) interface of TMAZ and WNZ (d) WNZ.

The microstructural evolution during SRFSW was influenced by the external cooling medium. Figure 7 shows the EBSD micrographs in the WNZs of all the samples. From the figure, it can be observed that fine and equiaxed grains are present in WNZ of all the samples. This is because of the thermo-mechanical action of the pin, which causes dynamic recrystallization and severe plastic deformation in WNZ and results in crushing and 
breaking of elongated grains and forming fine and equiaxed grain structure. From the Figure, it can be observed that the SRFSW joint formed with the C-RJ cooling condition showed the minimum average grain size of $3.69 \mu \mathrm{m}$. In C-RJ, due to the uniform envelope of the water over the workpiece surface, the friction heat was absorbed continuously. Thus, the heat input was very less. The grain deformation was caused only because of severe plastic deformation and sharing of the material by the pin leading to the formation of the finer grain than all other joints. The SRFSW joint under NAC condition showed a maximum average grain size $(8.74 \mu \mathrm{m})$ among all the samples. This is because in NAC, heat dissipation majorly took place by convective heat transfer from the workpiece to air, and the rate of convective heat transfer was much lower compared to water. Thus, recrystallized grains undergo grain growth in NAC joints forming larger grains in WNZ compared to other cases.
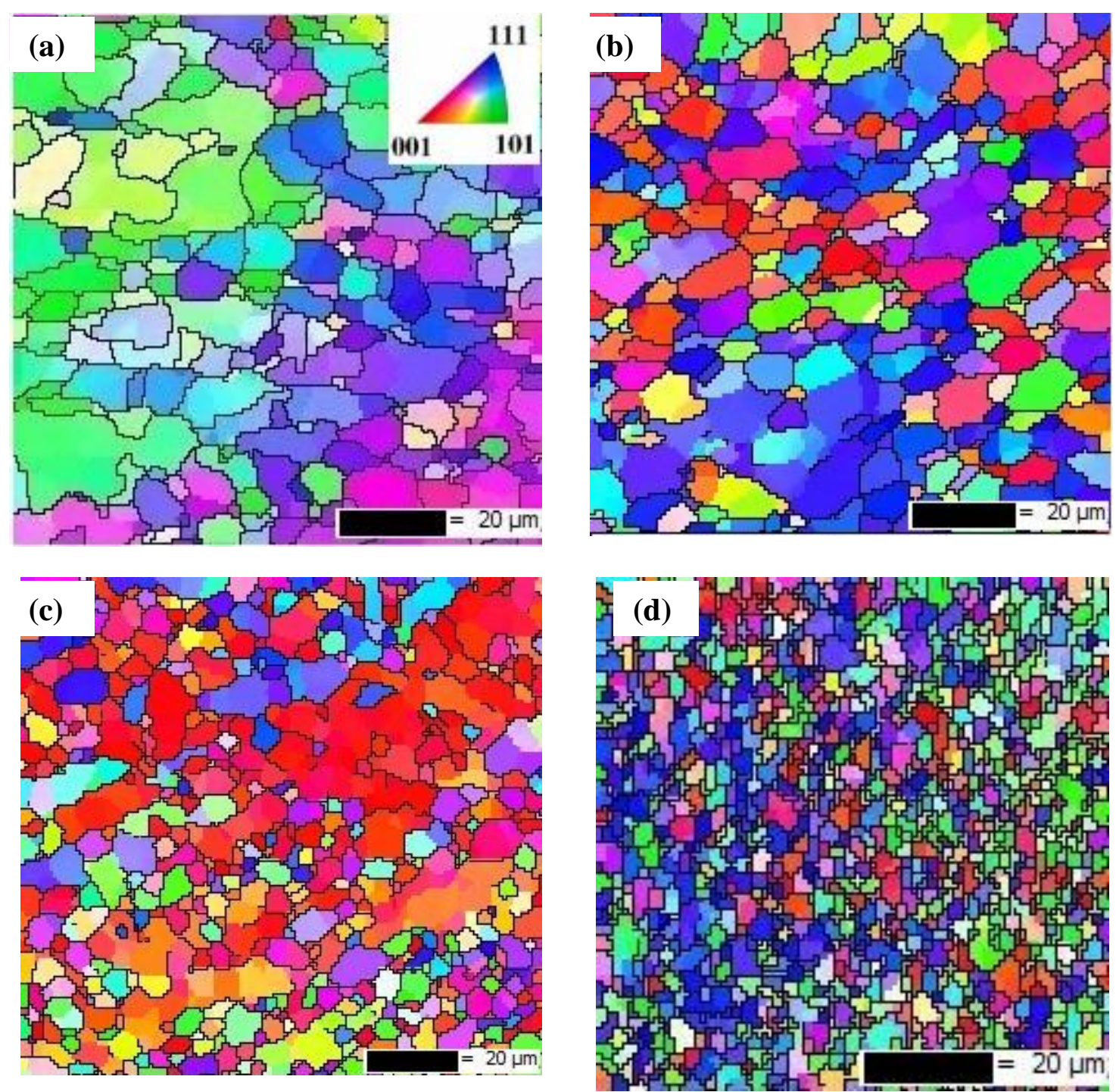

Figure 7. Grain structure in WNZ of (a) NAC (b) S-RM (c) S-IM (d) C-RJ.

\subsection{Tensile Properties}

The tensile properties of NAC, S-RM, S-IM, and C-RJ conditions are shown in Figure 8. The tensile strength of the as-welded joint i.e., NAC is $173.70 \mathrm{MPa}$. The tensile strength in S-RM and S-IM is $153.73 \mathrm{MPa}$ and $163.02 \mathrm{MPa}$ respectively. Even after using external cooling, the reduced strength in S-RM and S-IM cooling assisted joints can be attributed 
to abrupt and non-uniform heating and cooling because spraying of the water leads to non-uniform grain size in TMAZ resulting in early crack initiation and thus failure of joints. When compared two spraying conditions i.e., S-RM and S-IM, there is a $6.04 \%$ improvement in UTS value in the case of S-IM compared to S-RM. The graph shows the maximum tensile strength of $189.16 \mathrm{MPa}$ in the C-RJ condition which is $8.9 \%$ more than NAC. This is because of the uniform thermal gradient on both sides of the joint due to constant heat input as can be seen in the thermal cycle of C-RJ [38]. As per earlier investigations, the metastable phases $\beta^{\wedge \prime}$ and $\beta^{\wedge \prime}$ which are the greatest contributor to strength and hardness in Al-Mg-Si alloys are stable below $200{ }^{\circ} \mathrm{C}$ and can be dissolved or coarsen at high temperature due to high thermal input $[38,39]$. In NAC, S-RM, and S-IM joints, the peak temperature was more than $200{ }^{\circ} \mathrm{C}$ which was only $103^{\circ} \mathrm{C}$ in C-RJ. Thus, C-RJ might have retained metastable phases and resulted in improved tensile strength. We can conclude that the underwater cooling conditions exhibited equivalent or slightly enhanced strength due to controlled temperature distribution and uniform cooling rate.

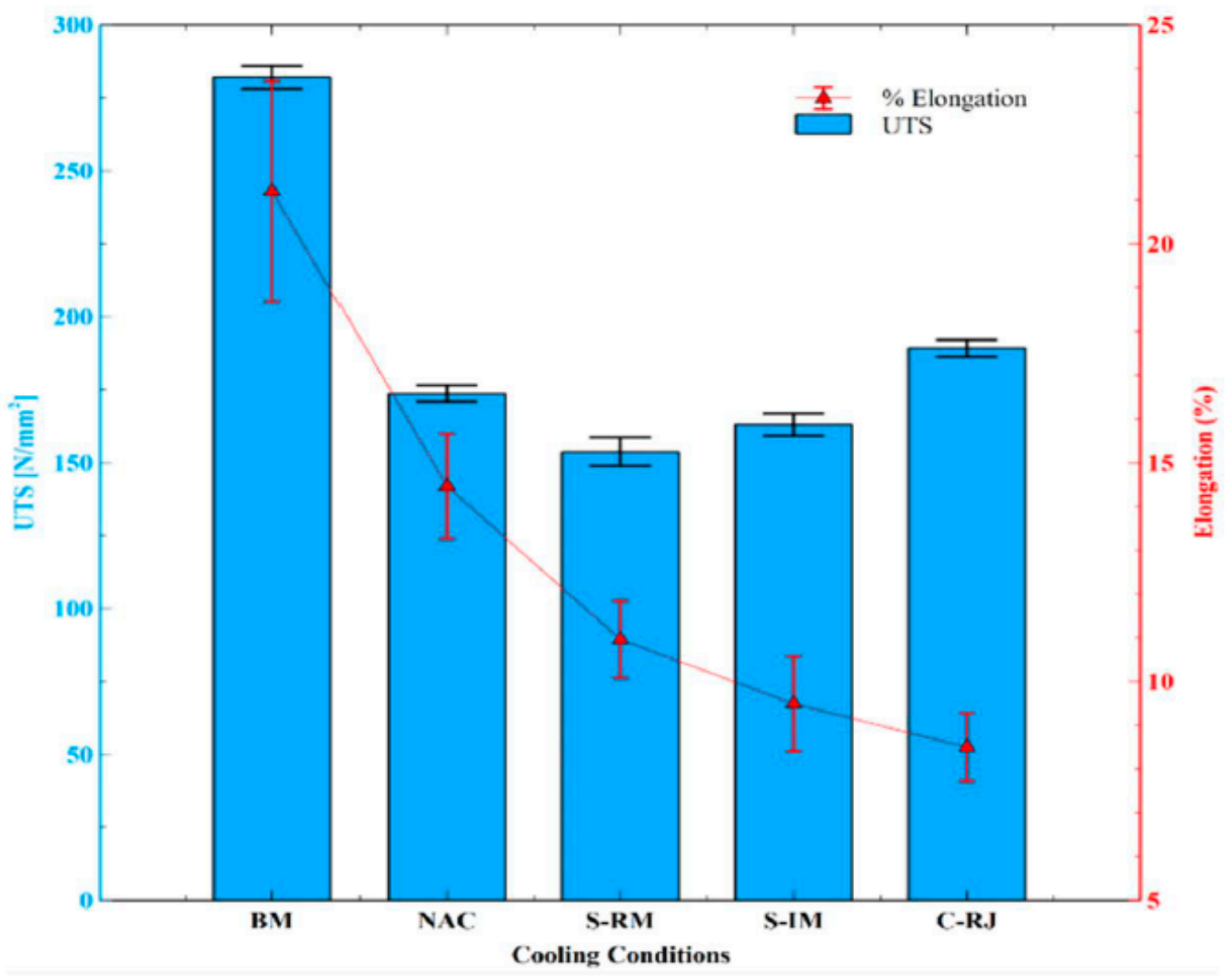

Figure 8. Tensile properties of joints produced with different cooling conditions.

The maximum elongation of $14.46 \%$ is observed in NAC. In NAC, the heat input at both sides of the workpiece was the same due to the same shoulder size and absence of external cooling. This resulted in uniform microstructure through-thickness leading to more ductility in joints. The minimum elongation of $8.50 \%$ was noted in C-RJ. This is can be attributed to three reasons: (1) low temperature generated in C-RJ causes the extensive restriction of plastic deformation and thus resulting in decreased elongation. (2) by applying uniform water cooling, the grain growth by thermal cycle is inhibited and finer microstructure in WNZ can be observed. This increases grain boundaries in microstructure and thus, decreases ductility of the joint. (3) low forming temperature in WNZ, narrowing of the softening region, and the presence of $\beta^{\wedge \prime}$ metastable phases resulted in a reduction in elongation in C-RJ joints. The elongation reported for S-RM and S-IM is $10.96 \%$ and $9.49 \%$ respectively. The reduced elongation is obtained in all cooling 
systems. The cooling action of the water restricted plastic deformation resulting in reduced elongation in all SRFSW joints welded with cooling systems.

\subsection{Microhardness of the Joint}

Figure 9 shows the microhardness variation along the centerline of the cross-section surface in the thickness direction. It can be seen from the graph that all the samples exhibited a symmetrical hardness distribution with $\mathrm{W}$-shaped microhardness profile. The $\mathrm{W}$ shaped profile is because of some hardness recovery in WNZ due to post-weld natural aging [9]. The low hardness zone (LHZ) is located at HAZ adjacent to TMAZ on AS in NAC joint while other joints exhibited LHZ in TMAZ adjacent to WNZ on AS. From the figure, it is also revealed that the hardness in WNZ is higher in all the samples. This can be attributed to finer grain size in WNZ compared to TMAZ and HAZ.

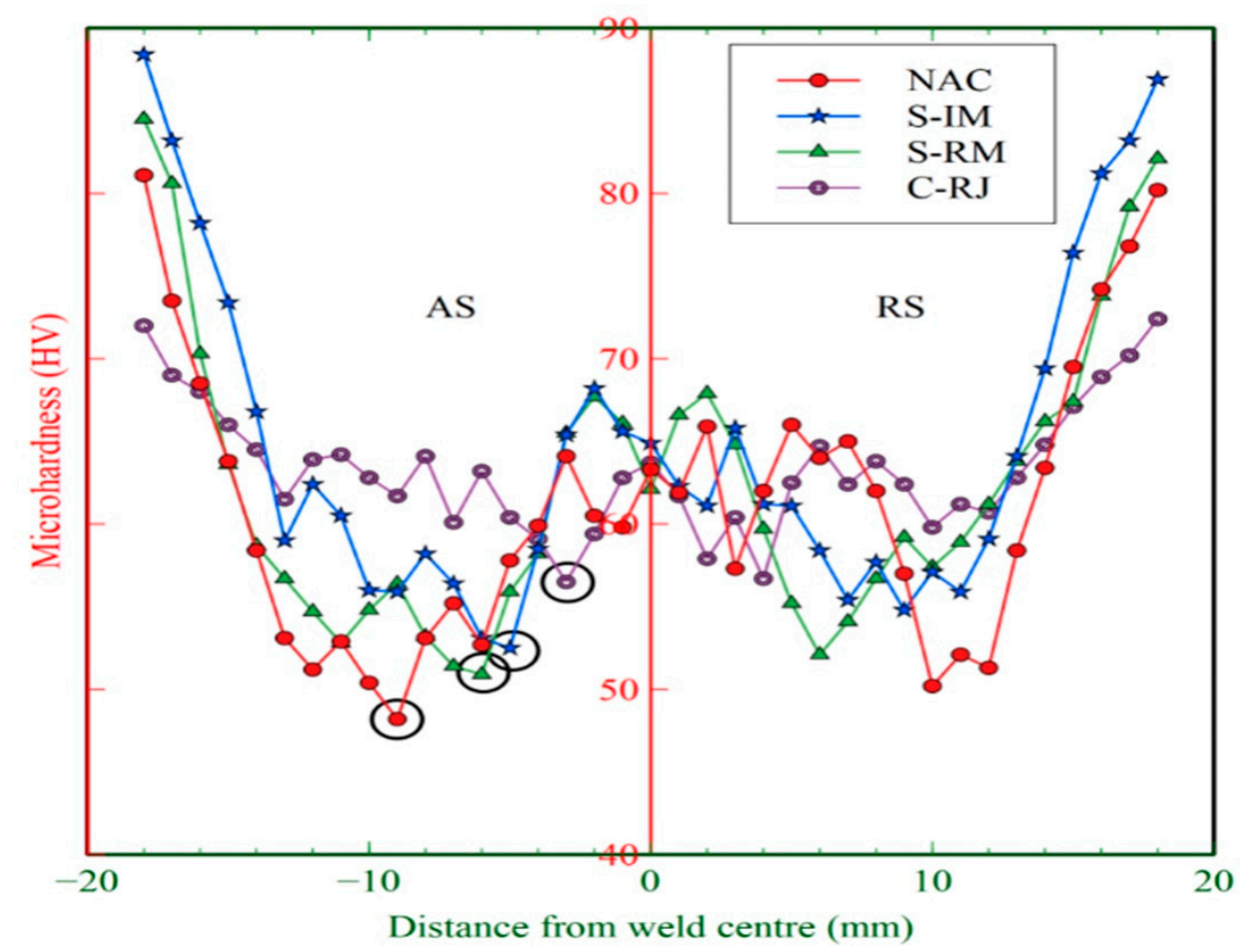

Figure 9. Hardness distribution across the joints obtained in different cooling conditions.

The lowest hardness zone observed for S-RM and S-IM was at the boundary of TMAZ and WNZ on AS while C-RJ exhibited LHZ in WNZ. This can be attributed to the narrowing of the softening zone and restrictions offered by water to heat generation. This shifted the minimum hardness zone from HAZ to the boundary of TMAZ / WNZ in cooling assisted welding. This minimum hardness is also consistent with the fracture location of cooling assisted welds. In all samples, the highest hardness $(\sim 56.5 \mathrm{HV})$ in LHZ can be observed in the case of C-RJ. In C-RJ, the top surface was continuously covered by water leading to a higher cooling rate which leaves less time for the precipitates to coarsen. Therefore, less coarsening of precipitates resulted in a rise in hardness of C-RJ joints. Additionally, the heat generated was rapidly transferred away from the processing zone, which significantly reduces the heat input. As a result, the flow stress of the processed zone increases leading to an increase in hardness of the C-RJ. On the other hand, in $\mathrm{NAC}$, the minimum hardness zone $(\sim 48.2 \mathrm{HV})$ was HAZ. In NAC, as peak temperature reached was $306^{\circ} \mathrm{C}$ which was sufficiently above the solvus of $\beta^{\prime \prime \prime}$ and $\beta^{\wedge \prime}$ resulting in dissolution and coarsening of metastable precipitated phases and thus forming LMZ in HAZ. When compared to spraying cooling conditions, S-IM showed higher hardness $(\sim 52.5 \mathrm{HV})$ in the lowest hardness zone than S-RM $(\sim 50.9 \mathrm{HV})$. This is because spraying 
with ice water resulted in a higher cooling rate due to the larger temperature between the plate and the cooling medium. This higher cooling rate inhibited the coarsening of strengthening precipitates in LHZ for S-IM resulting in more hardness compared to S-RM.

\subsection{Fractography}

The fracture morphologies of all the tensile test specimens are reported in Figure 10. All the samples exhibited fractures on AS. In NAC, the initiation and propagation of a crack in the HAZ on AS failed the joint. The fracture location is consistent with the lowest hardness zone of NAC. S-RM and S-IM cooling assisted SRFSW joints failed at the boundary of WNZ/TMAZ on AS, corresponding to the weakest hardness region of the joint. This is because the peak temperature in S-RM, S-IM was lower than NAC. Lower peak temperature leads to intense plastic deformation which results in finer grains and precipitates. However, lower peak temperatures might not have been sufficient for the proper mixing of plasticized material in SZ and TMAZ. This results in deterioration in strength and failure for S-RM and S-IM joints. The C-RJ joints failed in WNZ which is consistent with LHZ.

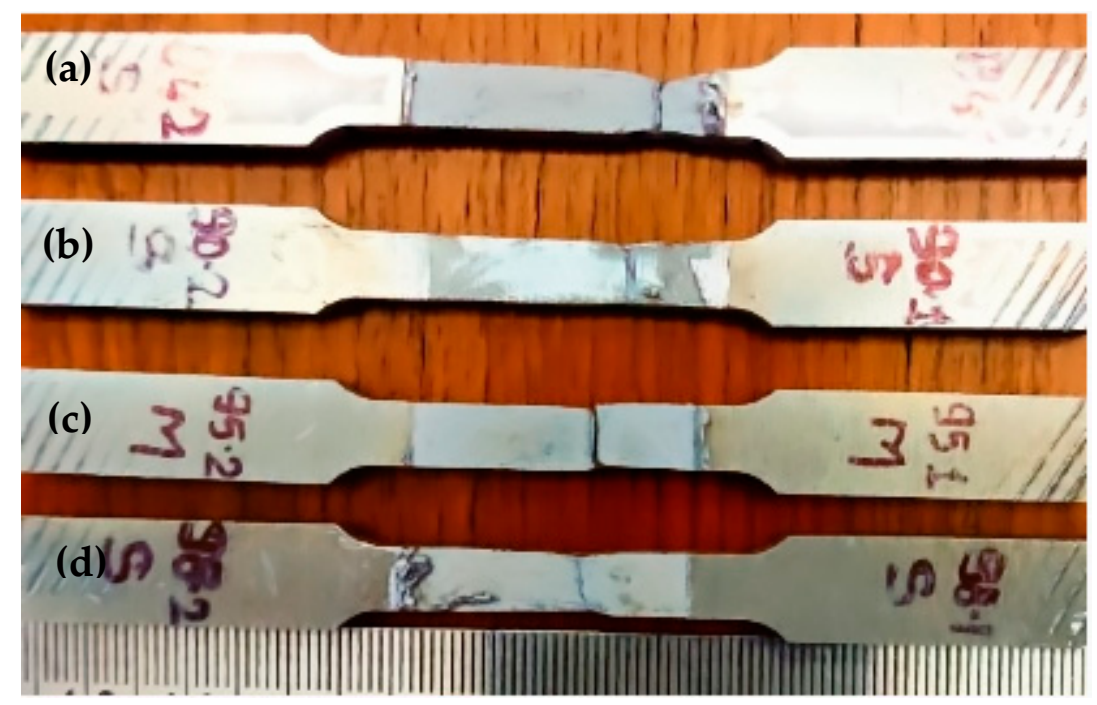

Figure 10. Fracture locations of the joints welded in different cooling conditions (a) NAC. (b) S-RM (c) S-IM (d) C-RJ.

Figure 11a-c shows the SEM image of the microstructure of the tensile fracture surface of NAC, S-IM, and S-RM joints, respectively. It can be seen that all the samples exhibited a large number of dimples which is characteristic of ductile fracture.

Dimples were deeper and highly populated in NAC as shown in Figure 11a indicating excellent plastic deformation which is responsible for higher ductility of the material. This is supported by the highest ductility reported for NAC joint among others. SEM morphology of S-IM (Figure 11b) showed shallow dimples compared to S-RM (Figure 11c) indicating less plastic deformation and less ductility compared to S-RM. The presence of large dimples with trans-granular cleavage facet in S-IM and S-RM compromised percentage elongation. Trans-granular cleavage facet has characteristic river-line pattern connected by shear edges showing crack propagation. The presence of trans-granular cleavage facet indicates early crack formation and hence failure of sample resulting in less elongation.

Figure 11d-f shows the SEM morphology of the C-RJ tensile fractured joint. The macrograph of the joint (Figure 11d) showed a V-pattern feature with stratification. The magnified view of A zone (Figure 11e) still presented large dimples indicating ductile fracture. The observation of stratification from V-pattern (Figure 11f) showed cleavage fracture with small dimples on the surface. Thus, it should be deducted that the C-RJ joint fractured due to mixed fracture resulting in the lowest ductility among all the joints. 

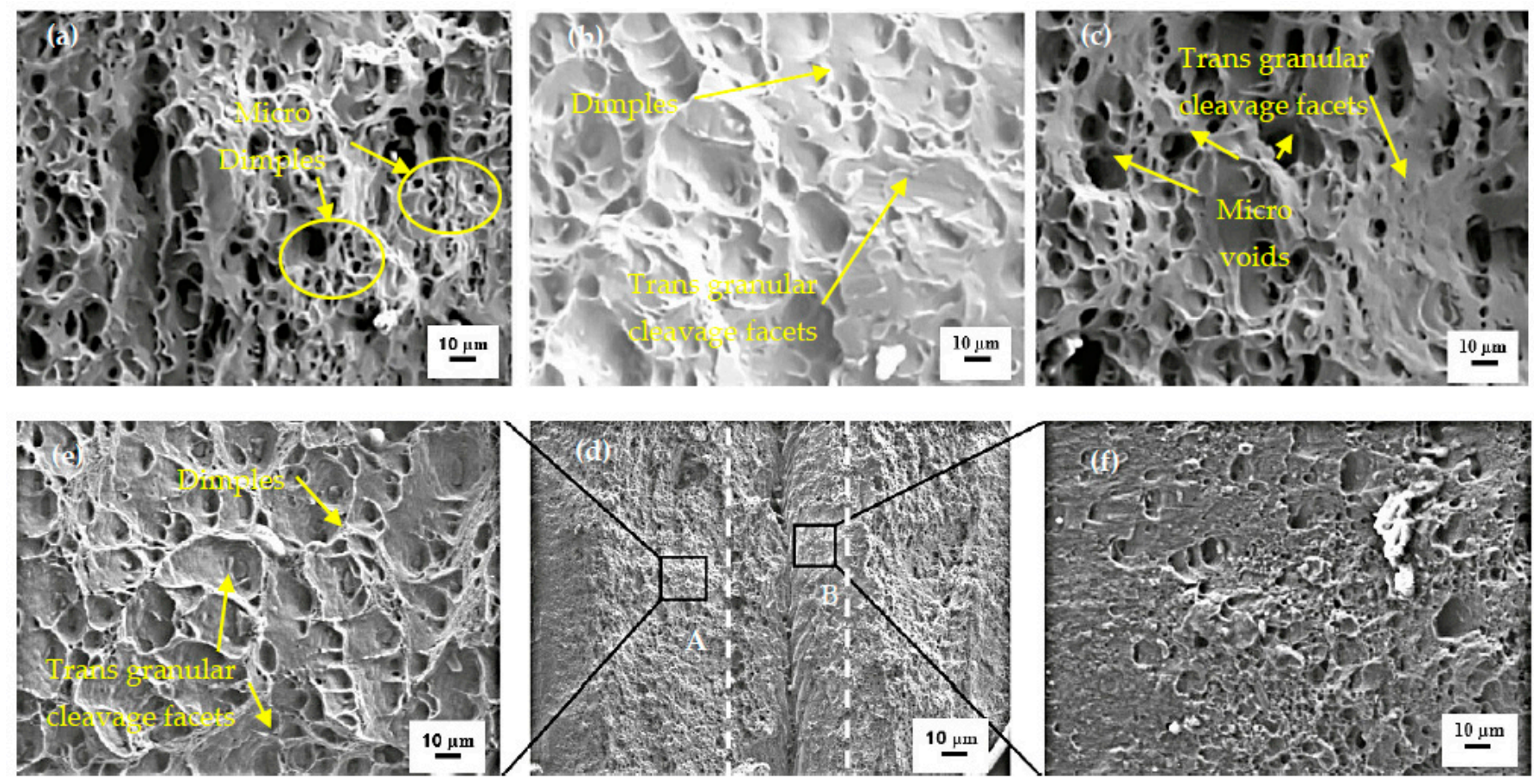

Figure 11. SEM morphology of fractured tensile joints (a) NAC (b) S-IM (c) S-RM (d) macro-fractograph of C-RJ (e) magnified A zone (f) magnified B zone.

\section{Conclusions}

In the present study, the results of investigations of the effect of different water temperature $\left(1{ }^{\circ} \mathrm{C}\right.$ and $\left.30^{\circ} \mathrm{C}\right)$ and techniques of using water (spraying and enveloping on the top surface) as cooling media on microstructure and mechanical properties on self-reacting friction stir welded $6 \mathrm{~mm}$ thick Al 6061-T6 aluminum alloy are reported. The following conclusions could be drawn:

(1) Coling systems S-RM, S-IM, and C-RJ resulted in a reduction of peak temperature by $11.39 \%, 15.71 \%$, and $35.05 \%$ respectively compared to peak temperature during NAC.

(2) The width of the top, middle, and bottom parts of WNZ are reduced in cooling assisted joints compared to the as-welded joint. The width of the bottom part was lower than the top part of WNZ in all the samples.

(3) SRFSW creates hourglass shape WNZ. The WNZ exhibited a fine and equiaxed microstructure for all the joints. The maximum and minimum average grain size of $18.68 \mu \mathrm{m}$ and $10.69 \mu \mathrm{m}$ was observed in NAC and C-RJ joints respectively. This concludes that the use of the water cooling media reduces grain size in WNZ.

(4) The maximum tensile strength of $189.16 \mathrm{MPa}$ which is $8.17 \%$ more than NAC was observed in C-RJ because of uniform thermal gradient and uniform cooling rate on both sides of the joint.

(5) Symmetrical microhardness distribution is obtained in all the welds. The highest hardness value $(\sim 56.5 \mathrm{HV})$ in the lowest hardness zone was observed in C-RJ due to a significant reduction in grain size.

(6) Natural air cooling assisted joints fractured in the heat-affected zone. However, the fracture location of S-RM and S-IM joints were shifted to the boundary of WNZ/TMAZ. The C-RJ joints failed from WNZ.

Author Contributions: Conceptualization, K.F. and V.B.; methodology, K.F.; validation, V.B.; formal analysis, K.F.; investigation, K.F. and V.B.; resources, V.B.; data curation, K.F.; writingoriginal draft preparation, K.F.; writing-review and editing, V.B.; visualization, K.F.; supervision, 
V.B.; project administration, V.B. All authors have read and agreed to the published version of the manuscript.

Funding: This research received no external funding.

Conflicts of Interest: The authors declare no conflict of interest.

$\begin{array}{ll}\text { Abbreviations } \\ \text { AS } & \text { Advancing side } \\ \text { BTFSW } & \text { Bobbin tool friction stir welding } \\ \text { FSW } & \text { Friction stir welding } \\ \text { HAZ } & \text { Heat affected zone } \\ \text { LAZ } & \text { Lowest hardness zone } \\ \text { NAC } & \text { Natural air cooling } \\ \text { SRFSW } & \text { Self-reacting friction stir welding } \\ \text { S-RM } & \text { Spraying with room temperature water mist } \\ \text { S-IM } & \text { Spraying with ice water mist } \\ \text { TMAZ } & \text { Thermo-mechanically affected zone } \\ \text { C-RJ } & \text { Cooling with room temperature water jet } \\ \text { WNZ } & \text { Weld nugget zone }\end{array}$

\section{References}

1. Zhou, L.; Li, G.H.; Liu, C.L.; Wang, J.; Huang, Y.X.; Feng, J.C.; Meng, F.X. Effect of Rotation Speed on Microstructure and Mechanical Properties of Self-Reacting Friction Stir Welded Al-Mg-Si alloy. Int. J. Adv. Manuf. Technol. 2017, 89, 3509-3516. [CrossRef]

2. Cisko, A.; Jordon, J.; Amaro, R.; Allison, P.; Wlodarski, J.; McClelland, Z.; Garcia, L.; Rushing, T. A Parametric Investigation on Friction Stir Welding of Al-Li 2099. Mat. Manuf. Process. 2020, 1-8. [CrossRef]

3. Li, Y.; Sun, D.; Gong, W. Effect of Tool Rotational Speed on the Microstructure and Mechanical Properties of Bobbin Tool Friction Stir Welded 6082-T6 Aluminum Alloy. Metals 2019, 9, 894. [CrossRef]

4. Tamadon, A.; Pons, D.J.; Sued, K.; Clucas, D. Thermomechanical grain refinement in AA6082-T6 thin plates under Bobbin friction stir welding. Metals 2018, 8, 375. [CrossRef]

5. Li, W.Y.; Fu, T.; Hütsch, L.; Hilgert, J.; Wang, F.F.; Dos Santos, J.F.; Huber, N. Effects of tool rotational and welding speed on microstructure and mechanical properties of bobbin-tool friction-stir welded Mg AZ31. Mater. Des. 2014, 64, 714-720. [CrossRef]

6. Ding, R.J.; Schneider, J.; Walker, B. Advances in Solid State Joining of Haynes 230 High Temperature Alloy. In Proceedings of the 8th International Symposium on Friction Stir Welding, Timmendorfer Strand, Germany, 18-20 May 2010.

7. Khorsid, A.; Moustafa, A.; Sabry, I. Investigation of the mechanical properties of Friction Stir Welded 6061 Al plates. Mater. Sci. Eng. 2001, 1-15. Available online: http:/ / www.jeaconf.org/UploadedFiles/Document/97626981-7e64-4048-8a70-6a0e1f6f9847.pdf (accessed on 22 December 2020).

8. Sahu, P.K.; Vasudevan, N.P.; Das, B.; Pal, S. Assessment of Self-Reacting Bobbin Tool Fiction Stir Welding for Joining AZ31 Magnesium Alloy at Inert Gas Environment. J. Magnes. Alloys 2019, 7, 661-671. [CrossRef]

9. Fuse, K.; Badheka, V. Bobbin Tool Friction Stir Welding: A Review. Sci. Technol. Weld Join. 2019, 24, 277-304. [CrossRef]

10. Verma, J.; Taiwade, R.V.; Reddy, C.; Khatirkar, R.K. Effect of Friction Stir Welding Process Parameters on Mg-AZ31B/Al-AA6061 Joints. Mat. Manuf. Process. 2018, 33, 308-314. [CrossRef]

11. Verma, S.; Misra, J.P. Effect of Process Parameters on Temperature and Force Distribution during Friction Stir Welding of Armor-Marine Grade Aluminum Alloy. Proc. Inst. Mech. Eng. Part B 2020. [CrossRef]

12. Verduzco Juárez, J.; Dominguez Almaraz, G.; García Hernández, R.; Villalón López, J. Effect of Modified Pin Profile and Process Parameters on the Friction Stir Welding of Aluminum Alloy 6061-T6. Adv. Mater. Sci. Eng. 2016. [CrossRef]

13. Vignesh, R.V.; Padmanaban, R.; Arivarasu, M.; Thirumalini, S.; Gokulachandran, J.; Ram, M. Numerical Modelling of Thermal Phenomenon in Friction Stir Welding of Aluminum Plates. IOP Conf. Ser. 2016, 012208. [CrossRef]

14. Shehabeldeen, T.A.; Abd Elaziz, M.; Elsheikh, A.H.; Hassan, O.F.; Yin, Y.; Ji, X.; Shen, X.; Zhou, J. A Novel Method for Predicting Tensile Strength of Friction Stir Welded AA6061 Aluminium Alloy Joints Based on Hybrid Random Vector Functional Link and Henry Gas Solubility Optimization. IEEE Access 2020, 8, 79896-79907. [CrossRef]

15. Goyal, A.; Garg, R.K. Parametric optimization of friction stir welding process for marine grade aluminum alloy. Int. J. Struct. Integr. 2019, 10, 162-175. [CrossRef]

16. Vijayan, S.; Raju, R.; Rao, S.K. Multiobjective optimization of friction stir welding process parameters on aluminum alloy AA 5083 using Taguchi-based grey relation analysis. Mater. Manuf. Process. 2010, 25, 1206-1212. [CrossRef]

17. Mehta, K.P.; Carlone, P.; Astarita, A.; Scherillo, F.; Rubino, F.; Vora, P. Conventional and Cooling Assisted Friction Stir Welding of AA6061 and AZ31B alloys. Mater. Sci. Eng. A 2019, 759, 252-261. [CrossRef]

18. Patel, P.; Rana, H.; Badheka, V.; Patel, V.; Li, W. Effect of Active Heating and Cooling on Microstructure and Mechanical Properties of Friction Stir-Welded Dissimilar Aluminium Alloy and Titanium Butt Joints. Weld World 2020, 64, 365-378. [CrossRef] 
19. Peng, G.; Yan, Q.; Hu, J.; Chen, P.; Chen, Z.; Zhang, T. Effect of Forced Air Cooling on the Microstructures, Tensile Strength, and Hardness Distribution of Dissimilar Friction Stir Welded AA5A06-AA6061 joints. Metals 2019, 9, 304. [CrossRef]

20. Lin, H.; Wu, Y.; Liu, S.; Zhou, X. Effect of Cooling Conditions on Microstructure and Mechanical Properties of Friction Stir Welded 7055 Aluminium Alloy Joints. Mater. Charact. 2018, 141, 74-85. [CrossRef]

21. Sinhmar, S.; Dwivedi, D. Enhancement of Mechanical Properties and Corrosion Resistance of Friction Stir Welded Joint of AA2014 Using Water Cooling. Mater. Sci. Eng. A 2017, 684, 413-422. [CrossRef]

22. Fathi, J.; Ebrahimzadeh, P.; Farasati, R.; Teimouri, R. Friction Stir Welding of Aluminum 6061-T6 in Presence of Watercooling: Analyzing Mechanical Properties and Residual Stress Distribution. Int. J. Lightweight Mater. Manuf. 2019, 2, 107-115. [CrossRef]

23. Liu, W.; Yan, Y.; Sun, T.; Wu, S.; Shen, Y. Influence of Cooling Water Temperature on ME20M Magnesium Alloy Submerged Friction Stir Welding: A Numerical and Experimental Study. Int. J. Adv. Manuf. Technol. 2019, 105, 5203-5215. [CrossRef]

24. Jalili, N.; Tabrizi, H.B.; Hosseini, M.M. Experimental and Numerical Study of Simultaneous Cooling with $\mathrm{CO}_{2}$ Gas during Friction Stir Welding of Al-5052. J. Mater. Process. Technol. 2016, 237, 243-253. [CrossRef]

25. Fujii, H.; Chung, Y.; Sun, Y. Friction Stir Welding of AISI 1080 Steel using Liquid $\mathrm{CO}_{2}$ for Enhanced Toughness and Ductility. Sci. Technol. Weld. Join. 2013, 18, 500-506. [CrossRef]

26. Satyanarayana, M.; Kumar, A. Influence of Cooling Media in Achieving Grain Refinement of AA2014 alloy using Friction Stir Processing. Proc. Inst. Mech. Eng. Part C 2020. [CrossRef]

27. Mehta, K.P.; Badheka, V.J. Hybrid Approaches of Assisted Heating and Cooling for Friction Stir Welding of Copper to Aluminum Joints. J. Mater. Process. Technol. 2017, 239, 336-345. [CrossRef]

28. Zhou, L.; Li, G.H.; Zha, G.D.; Shu, F.Y.; Liu, H.J.; Feng, J.C. Effect of rotation speed on microstructure and mechanical properties of bobbin tool friction stir welded AZ61 magnesium alloy. Sci. Technol. Weld. Join. 2018, 23, 596-605. [CrossRef]

29. Wang, F.F.; Li, W.Y.; Shen, J.; Hu, S.Y.; Dos Santos, J.F. Effect of tool rotational speed on the microstructure and mechanical properties of bobbin tool friction stir welding of Al-Li alloy. Mater. Des. 2015, 86, 933-940. [CrossRef]

30. Li, G.; Zhou, L.; Luo, S.; Huang, Y.; Guo, N.; Zhao, H.; Song, X. Effect of self-reacting friction stir welding on microstructure and mechanical properties of Mg-Al-Zn alloy joints. J. Manuf. Processes. 2019, 37, 1-10. [CrossRef]

31. Gaohui, L.I.; Li, Z.H.O.U.; Zhang, H.; Sanfeng, L.U.O.; Ning, G.U.O. Effects of traverse speed on weld formation, microstructure and mechanical properties of ZK60 Mg alloy joint by bobbin tool friction stir welding. Chin. J. Aeronaut. 2020. [CrossRef]

32. Li, G.; Zhou, L.; Luo, S.; Dong, F.; Guo, N. Microstructure and mechanical properties of bobbin tool friction stir welded ZK60 magnesium alloy. Mater. Sci. Eng. A 2020, 776, 138953. [CrossRef]

33. Li, G.H.; Zhou, L.; Luo, S.F.; Du, Z.Y.; Feng, J.C.; Meng, F.X. Microstructure and mechanical properties of self-reacting friction stir welded AA2219-T87 aluminium alloy. Sci. Technol. Weld. Join. 2020, 25, 142-149. [CrossRef]

34. Mardalizadeh, M.; Khandaei, M.; Safarkhanian, M.A. Influence of travel speed on the microstructural evaluation and mechanical characteristics of bobbin tool friction stir-welded thick AA5456-H112 plates. J. Adhes. Sci. Technol. 2020, 1-20. [CrossRef]

35. Zhao, Y.; Wang, C.; Dong, C. Microstructural Characteristics and Mechanical properties of Water Cooling Bobbin-Tool Friction Stir Welded 6063-T6 Aluminum Alloy. In MATEC Web of Conferences; EDP Sciences: Paris, France, 2018. [CrossRef]

36. Belhocine, A.; Abdullah, O.I. Structural and contact analysis of disc brake assembly during single stop braking event. Trans. Indian Inst. Met. 2015, 68, 403-410. [CrossRef]

37. Belhocine, A.; Bouchetara, M. Thermomechanical behaviour of dry contacts in disc brake rotor with a grey cast iron composition. Trans. Indian Inst. Met. 2012, 65, 231-238. [CrossRef]

38. Wahid, M.A.; Siddiquee, A.N.; Khan, Z.A.; Sharma, N. Analysis of Cooling Media Effects on Microstructure and Mechanical Properties During FSW/UFSW of AA 6082-T6. Mater. Res. Express 2018, 5, 046512. [CrossRef]

39. Hou, J.; Liu, H.; Zhao, Y. Influences of Rotation Speed on Microstructures and Mechanical Properties of 6061-T6 Aluminum Alloy Joints Fabricated by Self-Reacting Friction Stir Welding Tool. Int. J. Adv. Manuf. Technol. 2014, 73, 1073-1079. [CrossRef] 